\title{
Frontiers and challenges in soil respiration research: from measurements to model-data integration
}

\author{
Rodrigo Vargas • Mariah S. Carbone • \\ Markus Reichstein • Dennis D. Baldocchi
}

Received: 4 December 2009/Accepted: 2 May 2010/Published online: 22 May 2010

(C) The Author(s) 2010. This article is published with open access at Springerlink.com

\begin{abstract}
Soil respiration, the flux of $\mathrm{CO}_{2}$ from the soil to the atmosphere represents a major flux in the global carbon cycle. Our ability to predict this flux remains limited because of multiple controlling mechanisms that interact over different temporal and spatial scales. However, new advances in measurement and analyses present an opportunity for the scientific community to improve the understanding of the mechanisms that regulate soil respiration. In this paper, we address several recent advancements in soil respiration research from experimental measurements and data analysis to new considerations for modeldata integration. We focus on the links between the soil-plant-atmosphere continuum at short (i.e., diel) and medium (i.e., seasonal-years) temporal scales. First, we bring attention to the importance of
\end{abstract}

R. Vargas $(\bowtie) \cdot$ D. D. Baldocchi

Ecosystem Sciences Division, Department

of Environmental Science, Policy and Management,

University of California, Berkeley, CA 94720, USA

e-mail: rvargas@berkeley.edu

D. D. Baldocchi

e-mail: baldocchi@berkeley.edu

M. S. Carbone

Department of Geography, University of California,

Santa Barbara, CA 93106, USA

e-mail: mcarbone@icess.ucsb.edu

M. Reichstein

Max Planck Institute for Biogeochemistry, Jena, Germany

e-mail: mreichstein@bgc-jena.mpg.de identifying sources of soil $\mathrm{CO}_{2}$ production and highlight the application of automated soil respiration measurements and isotope approaches. Second, we discuss the need of quality assurance and quality control for applications in time series analysis. Third, we review perspectives about emergent ideas for modeling development and model-data integration for soil respiration research. Finally, we call for stronger interactions between modelers and experimentalists as a way to improve our understanding of soil respiration and overall terrestrial carbon cycling.

Keywords ${ }^{14} \mathrm{C}$ and ${ }^{13} \mathrm{C}$. Data assimilation . Isotopes - Model performance - Radiocarbon · Soil $\mathrm{CO}_{2}$ efflux $\cdot$ Soil sensors $\cdot$ Wavelet analysis

\section{Introduction}

Soil respiration or soil $\mathrm{CO}_{2}$ efflux has been studied for over 80 years (Lundegardh 1927). However, our inability to understand the mechanisms driving this flux limits our capacity to predict future atmospheric $\mathrm{CO}_{2}$ concentrations under different climate and global change scenarios. Complications arise because of multiple controlling mechanisms that interact over several temporal scales (hours to millennia), and depend on complex biological (i.e., plant and microbial) and physical (e.g., diffusion, mass transport, photodegradation) factors (Davidson and Janssens 2006; Heimann and Reichstein 2008; Trumbore 2006). 
In principle, soil respiration is defined as the combination of two biological sources, autotrophic respiration by plant roots and associated microorganisms (i.e., rhizosphere respiration), and heterotrophic respiration via microbial decomposition of soil organic matter (Hanson et al. 2000; Högberg and Read 2006; Ryan and Law 2005). In this manuscript, we will concentrate only on these biological components, however, in some ecosystems, carbonate weathering (Morner and Etiope 2002) or photodegradation (Austin and Vivanco 2006) can contribute significantly to the soil $\mathrm{CO}_{2}$ efflux.

Analyzing and understanding the dynamics of soil respiration demand different levels of complexity depending on the spatial and temporal scale of interest. One level of analysis is at the spatial scale of a few meters and at the temporal scale of the growing season where few measurements in space and time may be enough to describe the seasonal pattern in soil respiration. Another level of analysis involves the links between the soil-plant-atmosphere continuum at short (e.g. daily) and medium (e.g. seasons-years) temporal scales where a combination of techniques and multiple temporal and spatial observations are required. A third, and more general level of analysis is when soil respiration is studied at large spatial scales (e.g. regional-continental) where emerging properties on the soil-plant-atmosphere continuum are influenced by long-term processes (e.g. years-millennia) of climate patterns, vegetation type and carbon (C) stored in soils. This level is important for long-term sources and sinks of soil $\mathrm{C}$ and is sensitive to climate change (Davidson and Janssens 2006). For our purposes, we will focus on the soil-plant-atmosphere continuum at short and medium temporal scales because most of the $\mathrm{CO}_{2}$ efflux comes from faster cycling $\mathrm{C}$ sources (Högberg and Read 2006). Thus, we do not directly address issues of long-term dynamics of soil $\mathrm{C}$ as they pertain to the third level of complexity. However, we recognize that it is important to understand all levels and a combination of multiple methods/techniques are needed to properly address short and long-term terrestrial ecosystem $\mathrm{C}$ dynamics.

Difficulties in observing and quantifying belowground processes have been a major challenge towards understanding soil respiration, and several reviews have addressed soil respiration methodological approaches within the last decade (Hanson et al.
2000; Kuzyakov 2006; Raich and Schlesinger 1992; Raich and Tufekcioglu 2000; Ryan and Law 2005; Subke et al. 2006). However, recent technological advances in soil respiration measurements (e.g. automated measurements, and isotope measurements) are providing unprecedented information at multiple temporal scales (Carbone and Vargas 2008).With these new resources, the scientific community could improve the understanding of the processes that regulate soil respiration to move beyond empirical models that are driven primarily by simple temperature and soil moisture relationships (Davidson et al. 2006; Kuzyakov and Gavrichkova 2010).

The scientific community faces several key unanswered questions for developing process-based models of soil respiration at short and medium temporal scales. These include: (1) What is the role of plants and associated microorganisms in regulating soil respiration? (2) What are the time lags between $\mathrm{C}$ fixation and its return to the atmosphere by autotrophic and heterotrophic respiration? (3) What are the key processes/ mechanisms that regulate these return times?

The primary objective of this paper is to highlight innovative directions in soil respiration research. First, we highlight a few new experimental and technical advances. Second, we discuss challenges and potential analyses with continuous measurements of soil respiration. Third, we present new perspectives on modeling development and model-data integration. Finally, we conclude with a recommendation for stronger interactions between experimental and modeling scientists as the most promising way to improve our understanding of terrestrial $\mathrm{C}$ cycling.

\section{New measurement techniques}

Continuous measurements of soil respiration

Our understanding of the mechanisms that regulate soil respiration is mostly based on sporadic manual measurements (Bond-Lamberty and Thomson 2010) that do not accurately represent daily and seasonal patterns because they miss many days of the year, nighttime fluxes, phenology, and episodic events such as precipitation pulses. The more recent availability of automated soil respiration measurements now provides sub-hourly information to observe short-term variation in soil respiration. Over longer timescales 
(e.g., seasonal-interannual), these automated measurements allow for better estimates of the magnitude of soil respiration and can complement tower-based (i.e., eddy covariance) ecosystem (Lavigne et al. 1997) and understory (Baldocchi and Meyers 1991) measurements for site-level C balance approximations. Thus, with automated soil respiration measurements we can observe temporal variability in soil respiration (i.e., hourly-interannual), and obtain high time resolution input parameters for models.

Two primary methods of automated measurements of soil respiration have been developed. The first method includes both open (through flow) and closed chambers (circular flow) measurements (Goulden and Crill 1997; Irvine et al. 2008; Pumpanen et al. 2004; Savage and Davidson 2003). Automated chambers measure the $\mathrm{CO}_{2}$ flux at the soil surface, and therefore integrate all biophysical processes that contribute to soil respiration. Previous studies have discussed in detail technical issues related with chamber-based measurements of soil respiration and are not discussed here (Hutchinson and Rochette 2003; Pumpanen et al. 2004; Rochette et al. 1992; Savage and Davidson 2003).

The second method to measure soil respiration involves automated soil $\mathrm{CO}_{2}$ concentration profiles using gas wells (Hirsch et al. 2004; Risk et al. 2002a) or solid state $\mathrm{CO}_{2}$ sensors (Hirano et al. 2003). With soil $\mathrm{CO}_{2}$ concentrations profiles, the location of production of $\mathrm{CO}_{2}$ within the soil profile can be determined (Hashimoto and Komatsu 2006; Risk et al. 2002b), but the calculation of soil respiration is dependent on the proper estimate of multiple physical factors such as: (1) variation in soil water content that change $\mathrm{CO}_{2}$ diffusivity in the soil (Šimůnek and Suarez 1993); and (2) the proper estimation of tortuosity, soil texture, bulk density and porosity which are difficult to determine in rocky soils or water saturated soils (Jassal et al. 2005; Pumpanen et al. 2008; Turcu et al. 2005). Despite limitations of both methods, when used in combination, multiple studies have shown good agreement between the two (Jassal et al. 2005; Tang et al. 2005b; Turcu et al. 2005; Vargas and Allen 2008b).

One valuable product of automated measurements of soil respiration is the ability to observe diel patterns. There is evidence that diel cycles can be large and change abruptly day to day. For example during the early growing season in a semi-arid shrub ecosystem, soil respiration is tightly coupled to soil temperature until day of the year (DOY) 126 (Fig. 1a). Immediately after DOY 126, soil respiration is decoupled from soil temperature during the mid-day, and progressively more decoupled with any measured temperature (air, soil at multiple depths) throughout the growing season. Carbone et al. (2008) postulated that these patterns are regulated by differences in the timing and contribution of heterotrophic and autotrophic respiration in this ecosystem. Similar patterns have been observed across different vegetation types (Bahn et al. 2008; Baldocchi et al. 2006; Tang et al. 2005a; Vargas and Allen 2008a, b). However, in other ecosystems the apparent decoupling between soil respiration and soil temperature may be a result of physical processes such as changes in heat and $\mathrm{CO}_{2}$ transport in the soil as shown by modeling approaches (Jassal et al. 2004; Pumpanen et al. 2003).

A second application of automated measurements is the potential to measure the location of soil $\mathrm{CO}_{2}$ production deeper in the soil using $\mathrm{CO}_{2}$ concentrations profiles (Risk et al. 2002b), and then related the production with biophysical factors (Hasselquist et al. 2010; Vargas et al. 2010a). For example, in an oak woodland savannah a vertical array of soil $\mathrm{CO}_{2}$ sensors have been installed to test differences in soil $\mathrm{CO}_{2}$ production between trees and grasses (Baldocchi et al. 2006; Vargas et al. 2010a). During the dry season the annual grasses are dead and the upper soil layers are dry, but the trees with deeper roots are active and higher soil $\mathrm{CO}_{2}$ production is observed at a deeper layer (up to $60 \mu \mathrm{mol} \mathrm{CO}_{2}$ $\mathrm{m}^{-3} \mathrm{~s}^{-1}$, Fig. 1b). In contrast, during the winter rains when the annual grasses are active but the deciduous trees are inactive, soil $\mathrm{CO}_{2}$ production is higher at shallow depths but with substantially lower magnitudes (up to $8 \mu \mathrm{mol} \mathrm{CO}_{2} \mathrm{~m}^{-3} \mathrm{~s}^{-1}$, Fig. 2b) than during the dry season associated with higher tree photosynthesis rates. Mechanisms that influence soil $\mathrm{CO}_{2}$ production at the top layers of the soil may be different than those that regulate production at deeper soil layers because of differential spatial distributions of heterotrophic and autotrophic respiration sources, and changes in soil $\mathrm{CO}_{2}$ diffusion across seasons.

A third application of automated soil respiration measurements is the ability to measure the response of soils to stochastic precipitation pulse events (Fig. 2, Daly et al. 2008). The rapid rewetting of 
Fig. 1 Examples of diel patterns of soil respiration in a semi arid ecosystem modified from Carbone et al. (2008) showing soil temperature (grey and dashed line) and the sudden shift in the diel pattern of soil respiration (black) and b continuous measurements of soil $\mathrm{CO}_{2}$ production in an oak woodland from Vargas et al. (2010a) during dry season when trees are active but grasses are dead, and wet season when grasses are active but deciduous trees have no leaves
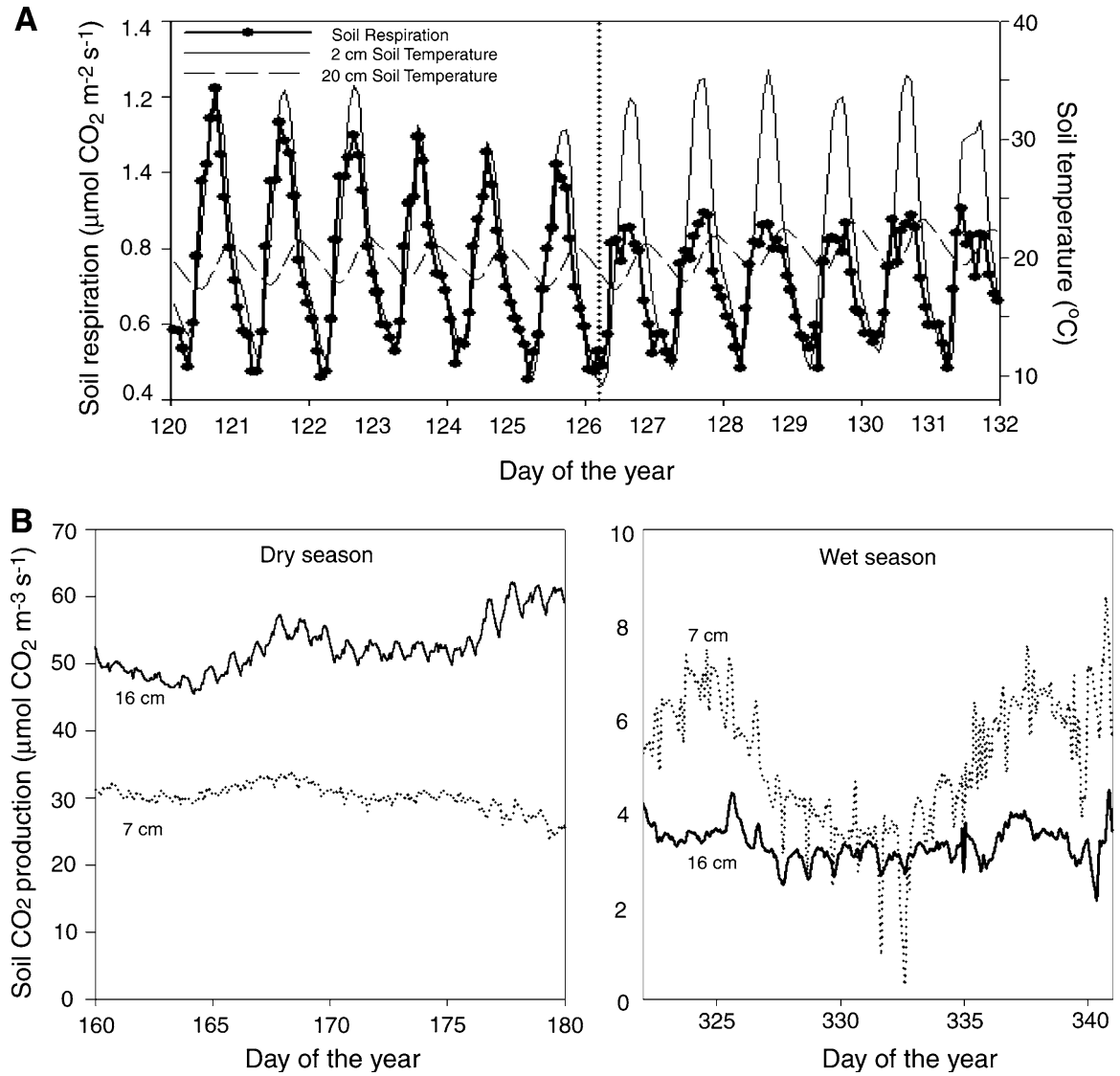

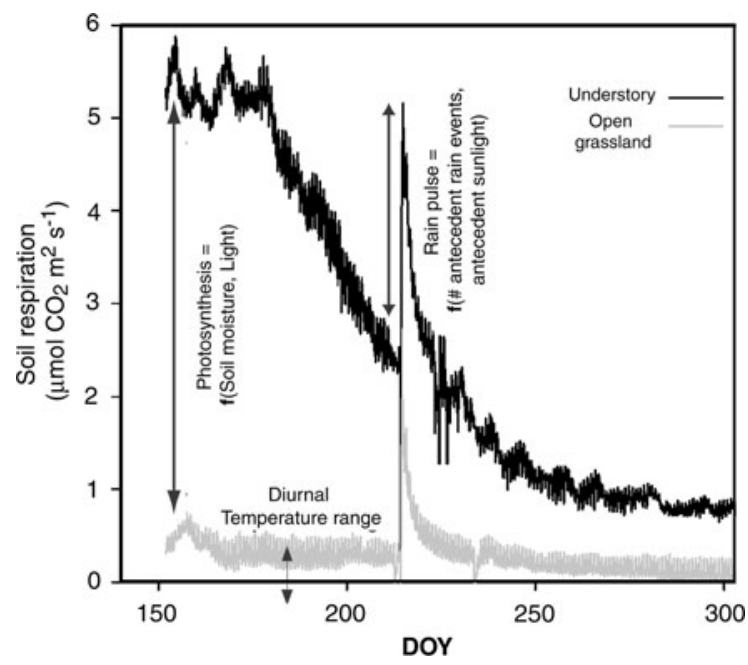

Fig. 2 Continuous measurements of soil respiration after a rain pulse event in the understory (black) and open grassland (grey) of a Mediterranean oak woodland. In this ecosystem photosynthesis is a function of soil moisture and light, but the soil respiration response is a function of number of antecedent rain events and antecedent sunlight (Baldocchi et al. 2006) soils may yield a pulse in soil $\mathrm{CO}_{2}$ production that may persist for several days (Fierer and Schimel 2003) and could contribute to a large percentage of ecosystem respiration (Xu and Baldocchi 2004). Multiple efforts have been done to identify processes that regulate soil $\mathrm{CO}_{2}$ production after water pulses such as the 'Birch Effect' (Birch 1959; Jarvis et al. 2007), or the relationship between photosynthesis and number of antecedent rain events (Xu and Baldocchi 2004). Now with automated soil respiration measurements one can measure the patterns of soil $\mathrm{CO}_{2}$ production after a rain pulse event and estimate the contribution of soil $\mathrm{CO}_{2}$ pulses for the annual soil respiration budget.

Isotope approaches

Isotopic approaches are promising experimental techniques to obtain direct, quantitative links to plant and microbial mechanisms driving variation in soil respiration (Bowling et al. 2008; Hanson et al. 2000; 
Paterson et al. 2009; Trumbore 2006, 2009). These links include quantifying (1) the transport of $\mathrm{C}$ within plants, (2) the transfer of $\mathrm{C}$ from roots to microbes, SOM, and/or respiration, and (3) the contributions to soil respiration from autotrophic and heterotrophic sources.

Experimentally separating soil respiration into autotrophic and heterotrophic sources is an important challenge facing current soil respiration research (Hanson et al. 2000; Kuzyakov and Gavrichkova 2010). Isotopic partitioning methods are advantageous over other techniques, such as trenching or girdling, because they impart much less disturbance to the plant-soil system. However, isotopic partitioning methods require that there be discernible differences between the isotopic signatures of autotrophic and heterotrophic sources (end members). For this reason, partitioning soil respiration with natural abundance ${ }^{13} \mathrm{C}$ has only been possible in ecosystems where there has been a shift in vegetation types using different photosynthetic (e.g. $\mathrm{C}_{3}$ and $\mathrm{C}_{4}$ ) pathways (Hanson et al. 2000; Kuzyakov 2006; Paterson et al. 2009; Subke et al. 2006).

Background abundance ${ }^{14} \mathrm{C}$ measured by accelerator mass spectrometry (AMS) is proving to be an effective approach for soil respiration partitioning. This is because in many ecosystems there are large differences in the $\Delta^{14} \mathrm{C}$ signatures of autotrophic and heterotrophic respiration due to differential incorporation of 'bomb' $\mathrm{C}$ (Gaudinski et al. 2000; Trumbore 2000). 'Bomb' $\mathrm{C}$ is the result of thermonuclear weapons testing in the 1950-60s in which the atmospheric concentration of ${ }^{14} \mathrm{CO}_{2}$ was increased almost two-fold. Since testing ceased in 1963, dilution from ocean and land $\mathrm{CO}_{2}$ exchange, and the burning of fossil fuels has caused the ${ }^{14} \mathrm{C}$ of the atmosphere to gradually decline (Levin and Hesshaimer 2000). Therefore, because the $\Delta^{14} \mathrm{C}$ signature of $\mathrm{C}$ in vegetation reflects that of the atmosphere in which it was photosynthesized, the $\Delta^{14} \mathrm{C}$ signatures of new photosynthetic products (the primary source for autotrophic respiration) is close to that of the current atmosphere. In contrast, the $\Delta^{14} \mathrm{C}$ signature of heterotrophic respiration is elevated with respect to the current atmosphere because it integrates decomposition from both new and accumulated SOM. On average, heterotrophic respiration reflects $\Delta^{14} \mathrm{C}$ signature of $\mathrm{C}$ photosynthesized years to decades earlier (when there was more 'bomb' $\mathrm{C}$ in the atmosphere;
Trumbore 2000). Thus, soil respiration can be separated in the field, using a simple isotope mass balance approach, where autotrophic and heterotrophic respiration 'end member' $\Delta{ }^{14} \mathrm{C}$ signatures are determined by separate incubations of roots and SOM respectively (Gaudinski et al. 2000; Schuur and Trumbore 2006).

To date, this approach has been used to look at autotrophic and heterotrophic contributions over seasonal to interannual timescales in temperate (Cisneros-Dozal et al. 2006; Gaudinski et al. 2000), boreal (Czimczik et al. 2006; Hahn et al. 2006; Schuur and Trumbore 2006), and semi-arid (Carbone et al. 2008) ecosystems; and with manipulations of rain (Borken et al. 2006) and snow (Muhr et al. 2009). In addition, ${ }^{14} \mathrm{C}$ partitioning may also be an effective approach to test more specific process-level hypotheses on shorter timescales, particularly when combined with automated soil respiration measurements (Carbone et al. 2008). Because ${ }^{14} \mathrm{C}$ is an indicator of age, these measurements can also be used to investigate the effects of moisture pulses on microbial decomposition of SOM (Fig. 2), and test the hypothesized mechanisms to explain the 'Birch Effect' (Birch 1959; Jarvis et al. 2007). For example, is the primary response of heterotrophic respiration after re-wetting due to (1) the mineralization of microbial cellular materials released with the rapid increase in water potential stress (younger C) or (2) the physical breakdown of soil aggregates exposing older, yet still readily decomposable C (Muhr and Borken 2009).

This technique is not without limitations, which have been thoroughly discussed (Bowling et al. 2008; Hanson et al. 2000; Paterson et al. 2009; Trumbore 2006, 2009). Still it is important to mention that it assumes that the isotopic signatures of the "end members' are representative. Capturing the heterotrophic respiration end member can be challenging, due to lateral spatial heterogeneity associated with new $\mathrm{C}$ inputs, but also due to vertical changes in the location of microbial decomposition with soil temperature and moisture variations. The autotrophic respiration end member can also vary (albeit less so) within ecosystems, across vegetation types, and seasonally depending on stored carbohydrate (older C) contributions to root respiration (Czimczik et al. 2006; Schuur and Trumbore 2006). Finally, ${ }^{14} \mathrm{C}$ measurements are expensive so studies are limited in 
the number of replicates in time and space, and interpretation of the results must take into account sample size and uncertainty within the measurements.

The addition of tracers to ecosystems to follow the fate of $\mathrm{C}$ belowground is another valuable isotopic approach. Tracer studies include both pulse- and continuous labeling applications with isotopically distinct (enriched or depleted, ${ }^{13} \mathrm{C}$ or ${ }^{14} \mathrm{C}$ ) substrates (e.g. $\mathrm{CO}_{2}$, litter, carbohydrates) introduced to the atmosphere or soil (Hanson et al. 2000; Kuzyakov 2006; Pataki et al. 2003; Pendall et al. 2004). Using ecosystem-level (i.e. field-based) $\mathrm{CO}_{2}$ pulse-labeling one can address issues about: (1) allocation on new $\mathrm{C}$ belowground (2) time lags between assimilation and soil respiration, (3) the role of photosynthesis and substrate supply in modulating soil respiration on the diel timescale, and (4) the transfer of $\mathrm{C}$ to microbial pathways.

Enhanced detection of ${ }^{14} \mathrm{C}$ measured by AMS now allows for low-level ${ }^{14} \mathrm{C}$ pulse-label applications (i.e. amounts well-below regulated health standards) in natural ecosystems. This approach is particularly valuable to trace the contribution of new $\mathrm{C}$ into small and long-lived pools because the label signal strength can be easily 6 orders of magnitude greater than possible with ${ }^{13} \mathrm{C}$ (Carbone et al. 2007; Carbone and Trumbore 2007). In addition, AMS can now easily measure samples as small as $10 \mu \mathrm{g} \mathrm{C}$ (vs. $1 \mathrm{mg}$, Santos et al. 2007a, b), thus there is potential to capture labeled-C in specific compounds, like phospholipid fatty acids (PLFAs), and identify incorporation in different microbial $\mathrm{C}$ pathways (Kramer and Gleixner 2006; Kramer et al. 2010).

Novel ecosystem studies are also being conducted with ${ }^{13} \mathrm{C}$ pulse-labels. Högberg et al. (2008) traced the fate of new $\mathrm{C}$ through various tree components, and into microbial pools. Most recently, Bahn et al. (2009) reported an innovative study in which ${ }^{13} \mathrm{C}$ of soil respiration was measured by tunable diode laser absorption spectrometry (TDLAS). This combination of high-temporal resolution ${ }^{13} \mathrm{C}$ measurements of soil respiration (i.e. real-time isoflux) plus manipulations of photosynthesis (shading) enabled new insights into substrate supply and aboveground links with soil respiration on the diel to weekly timescale. This approach is promising, particularly with the development and maturity of more field-worthy laser technologies, such as cavity-ring down spectroscopy (Wahl et al. 2006).

\section{Exploring continuous measurements of soil respiration}

The importance of quality assurance $\left(Q_{\mathrm{a}}\right)$, quality control $\left(Q_{\mathrm{c}}\right)$ and gap filling

Increases in dataset length, due to new automated measurements of soil respiration, will require specific protocols for $Q_{\mathrm{a}} / Q_{\mathrm{c}}$ and gap filling. These protocols are important to produce clean time series that are useful for subsequent analyses and data-model fusion. Examples have been proposed for data quality and calculation of uncertainties with automated soil respiration chambers (Savage et al. 2008). Furthermore, the scientific community using the eddy covariance method, which measures the molar density of $\mathrm{CO}_{2}$ and vertical wind perturbation to calculate fluxes of $\mathrm{CO}_{2}$ between ecosystems and the atmosphere (Baldocchi 2003; Goulden et al. 1996; Valentini et al. 1996), has detailed standardized methods for data $Q_{\mathrm{a}} / Q_{\mathrm{c}}$ (Papale et al. 2006). Future gap-filling approaches of automated measurements of soil respiration could incorporate non-linear regression, marginal distribution sampling, or artificial neural network based techniques (see Moffat et al. 2007). These techniques have been widely tested for gap filling of eddy covariance data and could be easily adapted for soil respiration research. Common harmonization procedures for soil and ecosystem $\mathrm{CO}_{2}$ fluxes will benefit future synthesis activities to better understand terrestrial carbon fluxes.

Time series analyses on soil respiration research

Once continuous measurements of soil respiration have been revised for $Q_{\mathrm{a}} / Q_{\mathrm{c}}$ one can start analyzing the time series. It is evident that biophysical factors (e.g. temperature, soil moisture, photosynthesis) that regulate soil respiration operate on a wide range of temporal scales. Thus, we propose that complex spectral methods are valuable to understand the temporal correlation between soil respiration and those factors. New approaches with time series analyses could focus on the study of the frequency domain of soil respiration signals (both fluxes and isotopes) because they contain strong periodicities from diurnal to seasonal scales (Fig. 3). Identifying important periodicity on these signals can help to identify when different biophysical mechanisms 
are relevant for driving soil respiration fluxes. Time series analyses such as cross-correlation may not be appropriate because biometeorological signals, including time series of soil respiration, are nonstationary as they are subject to phenomena such as rain pulse events.

An alternative method is the use of wavelet analysis which has been widely used for climate research, and previous studies have discussed in detail this technique (Torrence and Compo 1998). Wavelet analysis performs the estimation of the spectral characteristics of a time series as a function of time. A close analysis of any continuous measurements of soil respiration will reveal that the signal changes with time over a range of time-periods from days to years (Fig. 3). Intermediate time-periods (i.e., weeks to months) need to be separately investigated because episodic and transient events (i.e., heat waves, rain pulses) substantially influence soil $\mathrm{CO}_{2}$ processes at multiple temporal scales (Vargas et al. 2010b).

A subsequent technique is wavelet coherence analysis, which is used to analyze the temporal correlation between two time series. This technique has also been explained and discussed in previous studies (Grinsted et al. 2004; Torrence and Compo 1998). For example, using wavelet coherence analysis one can identify the temporal correlation between soil respiration and soil temperature or soil respiration and soil moisture. Using this technique Vargas and colleagues (2010b) reported that the temporal correlations of the time series between soil respiration and soil temperature are not consistent with time. This means that the temporal correlation between these two time series may not be significant every day of the year because other biophysical factors (e.g. photosynthesis, changes in soil $\mathrm{CO}_{2}$ diffusion rates) may have a stronger control over the signal of soil respiration. If these temporal correlations are not consistent in time, then it may be important that future model development and model parameterization consider when variations in soil respiration are significantly influenced by soil temperature at multiple temporal scales.

This brings us to a final application of time series analysis, which is the possibility to test the performance of soil respiration models in the frequency domain. In other words, one could identify when a model fails (i.e. has large residuals). To date, model performance is mainly done in the time domain where the goal is to match the measurements with the model outputs (Fig. 4a). However, it is difficult to identify under which circumstances the model (empirical or process based) fails, and therefore testing the model
Fig. 3 Global wavelet power spectrum of over 2 years of measurements of soil respiration in a mixed temperate forest in southern California (Vargas et al. 2010b). Legends in figure indicate factors that potentially influence soil respiration at specific timeperiods (i.e. days, weeks, months and years). The $y$ axis represents how much "energy" or power is represented by the signal at specific time-periods

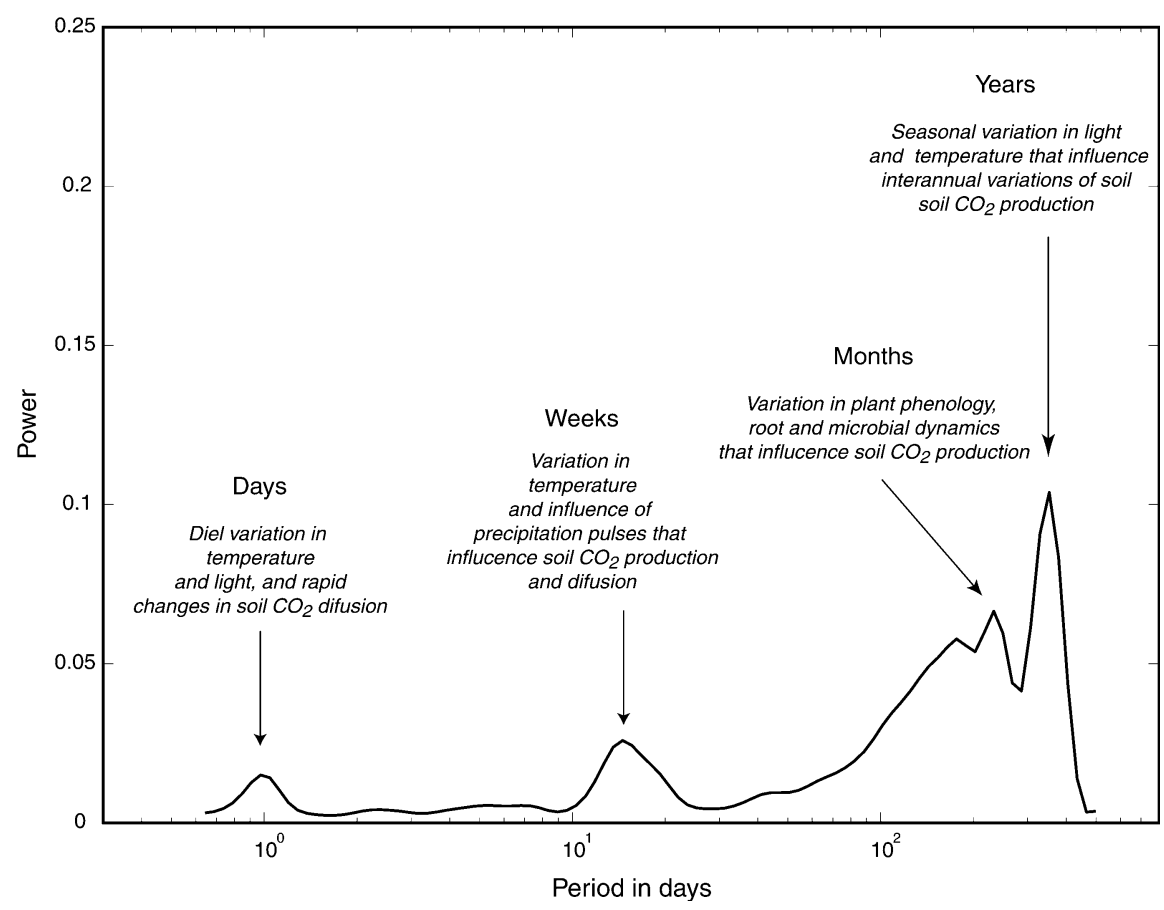



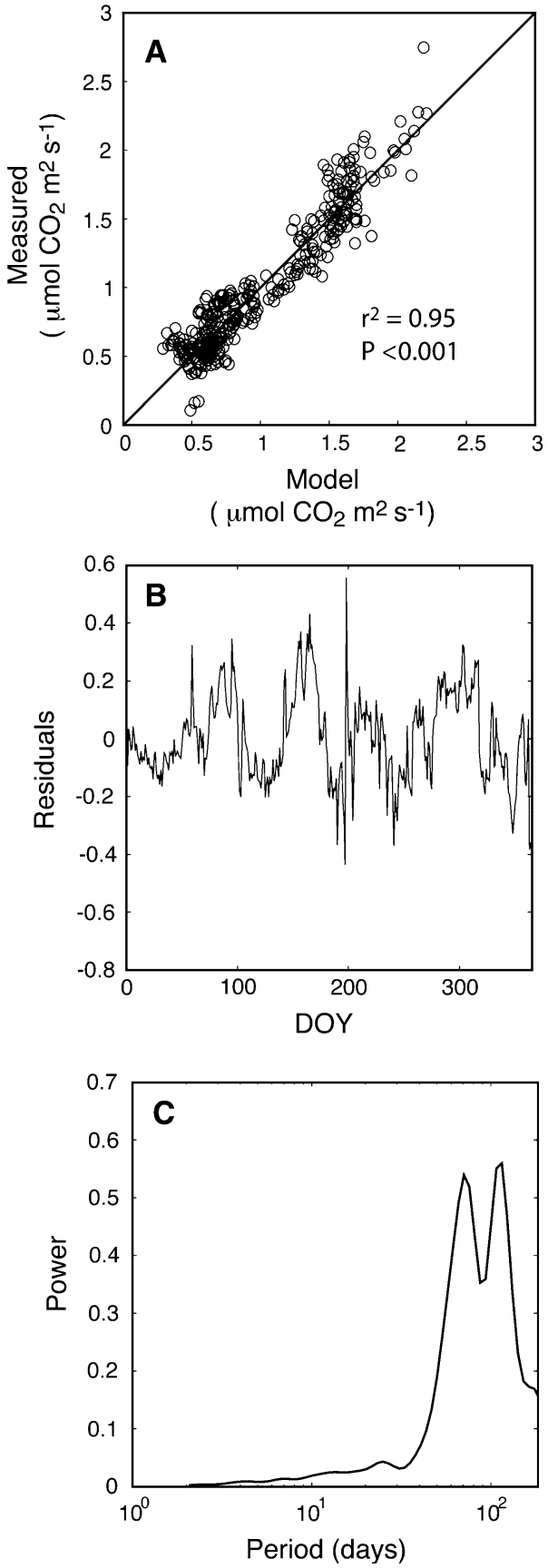

Fig. 4 a Comparison of model results and measurements of daily average of soil respiration in a mixed temperate forest in southern California (Vargas and Allen 2008b). Model results were calculated using the empirical relationship: soil respiration $=B_{0} \exp ^{\left(B_{1} T\right)} ;$ where $B_{0}$ and $B_{1}$ are constant model parameters and $T$ is soil temperature. b Residuals of the empirical model as a function of time. c Wavelet power spectrum of model residuals showing substantial model error at time-periods of 70 and 200 days output in the frequency domain may become more common (Vargas et al. 2010b). For example, one can estimate the residuals of a model (Fig. 4b) and then explore them in the frequency domain to identify at which time-periods (e.g., weeks, months, and years) the residuals are persistent. In our example, the empirical model has large residuals at time-periods of 70 and 200 days (Fig. 4c). Once these time-periods have been identified, one could revisit the model and modify it based on the information gathered in the frequency domain. An alternative approach is the application of Singular System Analysis (SSA) to extract specific oscillatory patterns as a way of decomposition of the time series to explore the temporal patterns of model performance at different time scales (Mahecha et al. 2010). If model development is not the goal one can use time series analysis to propose hypotheses for further research based on information about when the model fails.

\section{Perspectives on modeling development and model-data integration}

The scientific community is producing unprecedented datasets, and with this new data, new model developments and model-data integration exercises are expected. However, the modeling community is experiencing its own challenges and opportunities aided by the wealth of data collected in recent years. In this section we discuss our perspective about emergent ideas for modeling development and model-data integration for soil respiration research.

Model improvement is often hampered by inappropriate interpretation. One example is when process level parameters (e.g., enzyme activities) are mixed with whole-system level parameters (e.g., $Q_{10}$ of soil respiration) and both of these parameters are directly transferred into process models without accounting for confounding effects (Reichstein and Beer 2008). Therefore, one alternative treatment of the transition between scales (i.e., process level vs. whole-system level parameters) could be data-assimilation (Williams et al. 2009).

In the topic of soil respiration and $\mathrm{C}$ dynamics there are large uncertainties in model structure. Hence we caution the community that 'blind' data assimilation is not appropriate. We propose that data assimilation 
for soil respiration research should be replaced by a more general term 'model-data synthesis' or 'modeldata integration', which consists of several steps (Fig. 5). At each of these steps, there is interplay between data, model structure, and the model developer. The process detail depends somewhat on whether the problem is focused on state estimation of the system, or on parameter estimation of the model. If state estimation is the goal, then model states are adjusted to generate closer agreement with the observations. If model parameter estimation is the goal, then model parameters are adjusted so that the model state(s) come into closer agreement with the observations. Following the optimization of model parameters (defined here loosely to potentially include both parameters sensu stricto and state variables), it is critical that further analyses be conducted by the modeler to: (1) quantify uncertainties in optimized parameters; (2) evaluate the plausibility and temporal stability of optimized parameter values; (3) understand when and why the model is failing; and (4) identify opportunities for model improvement (e.g., re-formulation of structure and process representation). When treated in this manner, we propose that model data synthesis has relevance to both basic and applied scientific questions.

We briefly bring to attention to three interconnected problems, which occur with model-data fusion and complex models: equifinality, overparameterisation, and effective parameterization. Equifinality

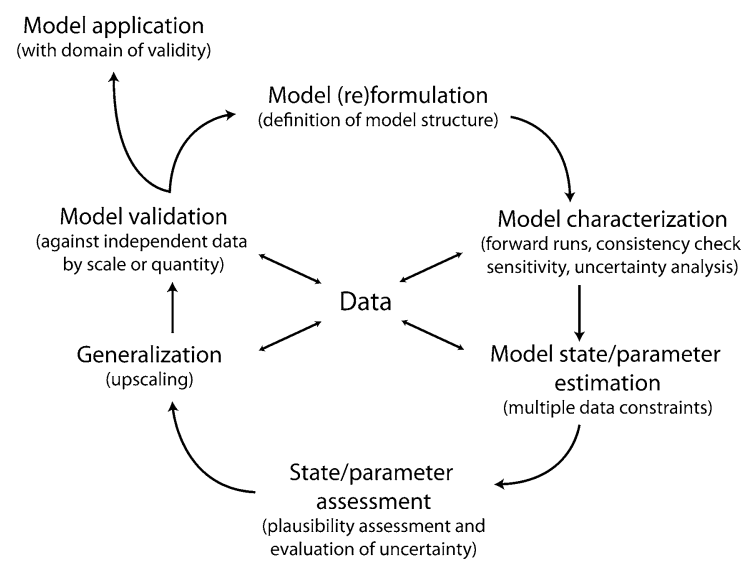

Fig. 5 The multi-step process for model-data fusion: a conceptual diagram showing the main steps (and the iterative nature of these steps) involved in a comprehensive data-model synthesis (after Williams et al. 2009) describes the fact, that a certain dataset can be described equally well by different models or model parameterizations (Luo et al. 2009; Williams et al. 2009). As an illustrative example, consider the $\mathrm{CO}_{2}$ flux from a soil compartment, which is often described as Flux $=$ pool $*$ rate constant, where the rate constant is the parameter and the pool a state variable. In this case many combinations of pool and rate constant can describe soil $\mathrm{CO}_{2}$ fluxes, if they are inversely related (i.e., the rate constant is not wellconstrained by the fluxes alone). Thus, additional measurements of pool sizes or combinations of pool estimates and fluxes may yield better constraints. Finally, one can make model experiments and suggest new empirical experimental approaches to test further hypotheses developed from this approach (Wutzler and Reichstein 2008).

It is known that process models try to generate system behavior (e.g., soil $\mathrm{CO}_{2}$ fluxes) by describing the sub-systems (i.e., autotrophic and heterotrophic respiration) and their interactions if possible from first principles. This often leads to models with many parameters, which are hard to parameterize (overparameterized models), and the above-mentioned equifinality problem could emerge. As shown by Reichert (1997) overparameterization often leads to highly correlated parameters. If this is the case, one can apply a Bayesian approach where prior information on the parameter distribution can be used for better model parameterization (Van Oijen et al. 2005).

Finally, we believe that the most critical problem is 'confounded parameterization'. It occurs when the model structure is too dissimilar from the real world where certain processes are missing, or when there are systematic data-biases. Under those conditions, parameters are found in model-data fusion approaches to best 'describe' the observations. However, they do not represent 'real' process parameters because they are statistically confounded parameters. Hence, the process model loses its predictive capacity, which should originate from a sound process representation because the confounded parameter does not describe the system behavior correctly under modified conditions. Statistical models, such as the one used to generate the "modeled values" in Fig. 4, also experience this problem.

The phenomenon of 'confounded parameterization' is critical because it is not easily detectable (in contrast to overparameterization which can be 
tested for instance by looking at the covariance matrix of the parameter estimates). Ignoring this phenomenon could degrade model-data fusion into a bad fitting exercise. There are several studies where effective parameterization has been identified to be important for terrestrial $\mathrm{C}$ cycling research. For example, the case of estimation of respiration temperature sensitivity can be overestimated by confounding seasonal cycles when one is analyzing the bulk (or total) timeseries data with a simple $Q_{10}$ model (Carrara et al. 2004; Reichstein et al. 2005). Furthermore, Carvalhais et al. (2008) showed that the steady state assumption in terrestrial $\mathrm{C}$ cycle models leads to effective and erroneous parameter estimates when the considered ecosystem is not in steady state. This is an area of active research where several techniques should be explored to avoid confounding effects with model parameterization. One example is the abovementioned separation of model performance in timescales (e.g. if by definition a model does not represent a certain time-scale it should not be evaluated against that). We propose that similar exercises should be done to avoid 'confounded parameterization' to study the influence of rain pulse events on soil respiration (Figs. 2, 3). In this case if a model does not describe the process behind them, the rain pulses could be interpreted as high (direct) sensitivity of soil respiration to moisture. This could lead the confounded (and erroneous) respective parameters, which for example would wrongly describe the response of the system to a mean change in soil moisture.

An ongoing challenge is to solve how the modeling community will cope with these problems for modeldata integration and model developing. Our intention is not to provide solutions for soil respiration modeling, but to address these emergent ideas to stimulate constructive scientific discussion. We are moving to an era of regional and global research networks that will continue collecting unprecedented biogeochemical information (e.g. FLUXNET, NEON, ICOS). With increasing data resources we need to move beyond empirical models and integrate the large amount of multiple observations (e.g. soil and ecosystems $\mathrm{CO}_{2}$ fluxes, isotope data) into process-based models that should represent the "breathing of the biosphere" at multiple temporal and spatial scales. This will require a stronger interaction between modelers and experimentalists to improve model structures and generate further hypothesis for future generations of ecosystem experiments.

\section{Future considerations}

Current technological advancements are helping to improve our understanding of biophysical processes that regulate soil respiration and terrestrial $\mathrm{C}$ cycling. Yet, major challenges remain ahead of us: (1) quantifying autotrophic and heterotrophic sources of soil respiration across different ecosystems in time and space, (2) understanding the control of vegetation on soil respiration including lags and transport of $\mathrm{C}$ from photosynthesis to soil respiration; (3) incorporating disturbances into process-based models; and (4) measuring in high resolution (spatially and temporally) and upscaling predictions of soil respiration and $\mathrm{C}$ storage to larger spatial scales (e.g. landscape-global) and temporal scales (e.g. interannual to millennia). Combining studies with multiple techniques including isotopes, automated measurements of soil respiration and soil $\mathrm{CO}_{2}$ production with ecosystem fluxes (i.e. eddy covariance) will yield complementary information about $\mathrm{C}$ cycle processes and may influence on how we parameterize and construct models. Traditionally, new experiments have been based on observations, however, researchers can learn from model results, and design new experiments to test further hypotheses developed by models. This approach can help improve both models and experiments. Thus, greater cooperation between modelers and experimentalists is a potentially powerful approach to increase our understanding of soil respiration and the underlying processes that drive this important flux.

Acknowledgments RV and DDB acknowledge support from the National Science Foundation grant DEB-0639235. MSC was supported by the NOAA Climate and Global Change Postdoctoral Fellowship Program, administered by the University Corporation for Atmospheric Research. MR is grateful for funding from the European Research Council via the ERC Grant QUASOM. This study was improved by a workshop held at the Wartburg, Jena, Germany and the comments of three anonymous reviewers.

Open Access This article is distributed under the terms of the Creative Commons Attribution Noncommercial License which permits any noncommercial use, distribution, and reproduction in any medium, provided the original author(s) and source are credited. 


\section{References}

Austin AT, Vivanco L (2006) Plant litter decomposition in a semi-arid ecosystem controlled by photodegradation. Nature 442(7102):555-558

Bahn M, Rodeghiero M, Anderson-Dunn M, Dore S, Gimeno C, Drosler M, Williams M, Ammann C, Berninger F, Flechard C, Jones S, Balzarolo M, Kumar S, Newesely C, Priwitzer T, Raschi A, Siegwolf R, Susiluoto S, Tenhunen J, Wohlfahrt G, Cernusca A (2008) Soil respiration in European grasslands in relation to climate and assimilate supply. Ecosystems 11(8):1352-1367

Bahn M, Schmitt M, Siegwolf R, Richter A, Bruggemann N (2009) Does photosynthesis affect grassland soil-respired $\mathrm{CO}_{2}$ and its carbon isotope composition on a diurnal timescale? New Phytol 182(2):451-460

Baldocchi DD (2003) Assessing the eddy covariance technique for evaluating carbon dioxide exchange rates of ecosystems: past, present and future. Glob Change Biol 9(4): 479-492

Baldocchi DD, Meyers TP (1991) Trace gas-exchange above the floor of a deciduous forest. 1. Evaporation and $\mathrm{CO}_{2}$ efflux. J Geophys Res Atmos 96(D4):7271-7285

Baldocchi D, Tang JW, Xu LK (2006) How switches and lags in biophysical regulators affect spatial-temporal variation of soil respiration in an oak-grass savanna. J Geophys Res 111(G2):Art. No. G02008

Birch HF (1959) Further observations on humus decomposition and nitrification. Plant Soil 9:262-286

Bond-Lamberty B, Thomson A (2010) Temperature-associated increases in the global soil respiration record. Nature 464:579-582

Borken W, Savage K, Davidson EA, Trumbore SE (2006) Effects of experimental drought on soil respiration and radiocarbon efflux from a temperate forest soil. Glob Change Biol 12(2):177-193

Bowling DR, Pataki DE, Randerson JT (2008) Carbon isotopes in terrestrial ecosystem pools and $\mathrm{CO}_{2}$ fluxes. New Phytol 178(1):24-40

Carbone MS, Trumbore SE (2007) Contribution of new photosynthetic assimilates to respiration by perennial grasses and shrubs: residence times and allocation patterns. New Phytol 76(1):124-135

Carbone MS, Vargas R (2008) Automated soil respiration measurements: new information, opportunities and challenges. New Phytol 177(2):295-297

Carbone MS, Czimczik CI, McDuffee KE, Trumbore SE (2007) Allocation and residence time of photosynthetic products in a boreal forest using a low-level C-14 pulse-chase labeling technique. Glob Change Biol 13(2):466-477

Carbone MS, Winston GC, Trumbore SE (2008) Soil respiration in perennial grass and shrub ecosystems: linking environmental controls with plant and microbial sources on seasonal and diel timescales. J Geophys Res (113): G09022. doi:09010.01029/02007JG000611

Carrara A, Janssens IA, Yuste JC, Ceulemans R (2004) Seasonal changes in photosynthesis, respiration and NEE of a mixed temperate forest. Agric For Meteorol 126(1-2):15-31

Carvalhais N, Reichstein M, Seixas J, Collatz GJ, Pereira JS, Berbigier P, Carrara A, Granier A, Montagnani L, Papale
D, Rambal S, Sanz MJ, Valentini R (2008) Implications of the carbon cycle steady state assumption for biogeochemical modeling performance and inverse parameter retrieval. Glob Biogeochem Cycl 22:GB2007

Cisneros-Dozal LM, Trumbore S, Hanson PJ (2006) Partitioning sources of soil-respired $\mathrm{CO}_{2}$ and their seasonal variation using a unique radiocarbon tracer. Glob Change Biol 12(2):194-204

Czimczik CI, Trumbore SE, Carbone MS, Winston GC (2006) Changing sources of soil respiration with time since fire in a boreal forest. Glob Change Biol 12(6):957-971

Daly E, Oishi AC, Porporato A, Katul GG (2008) A stochastic model for daily subsurface $\mathrm{CO}_{2}$ concentration and related soil respiration. Adv Water Resour 31:987-994

Davidson EA, Janssens IA (2006) Temperature sensitivity of soil carbon decomposition and feedbacks to climate change. Nature 440(7081):165-173

Davidson EA, Janssens IA, Luo YQ (2006) On the variability of respiration in terrestrial ecosystems: moving beyond Q(10). Glob Change Biol 12(2):154-164

Fierer N, Schimel JP (2003) A proposed mechanism for the pulse in carbon dioxide production commonly observed following the rapid rewetting of a dry soil. Soil Sci Soc Am J 67(3):798-805

Gaudinski JB, Trumbore SE, Davidson EA, Zheng SH (2000) Soil carbon cycling in a temperate forest: radiocarbonbased estimates of residence times, sequestration rates and partitioning of fluxes. Biogeochemistry 51(1):33-69

Goulden ML, Crill PM (1997) Automated measurements of $\mathrm{CO}_{2}$ exchange at the moss surface of a black spruce forest. Tree Physiol 17(8-9):537-542

Goulden ML, Munger JW, Fan SM, Daube BC, Wofsy SC (1996) Measurements of carbon sequestration by longterm eddy covariance: methods and a critical evaluation of accuracy. Glob Change Biol 2(3):169-182

Grinsted A, Moore JC, Jevrejeva S (2004) Application of the cross wavelet transform and wavelet coherence to geophysical time series. Nonlinear Process Geophys 11(5-6): 561-566

Hahn V, Hogberg P, Buchmann N (2006) C-14-a tool for separation of autotrophic and heterotrophic soil respiration. Glob Change Biol 12(6):972-982

Hanson PJ, Edwards NT, Garten CT, Andrews JA (2000) Separating root and soil microbial contributions to soil respiration: a review of methods and observations. Biogeochemistry 48:115-146

Hashimoto S, Komatsu H (2006) Relationships between soil $\mathrm{CO}_{2}$ concentration and $\mathrm{CO}_{2}$ production, temperature, water content, and gas diffusivity: implications for field studies through sensitivity analyses. J For Res 11(1):41-50

Hasselquist NJ, Vargas R, Allen MF (2010) Using soil sensing technology to examine interactions and controls between ectomycorrhizal growth and environmental factors on soil $\mathrm{CO}_{2}$ dynamics. Plant Soil 331:17-29

Heimann M, Reichstein M (2008) Terrestrial ecosystem carbon dynamics and climate feedbacks. Nature 451(7176):289-292

Hirano T, Kim H, Tanaka Y (2003) Long-term half-hourly measurement of soil $\mathrm{CO}_{2}$ concentration and soil respiration in a temperate deciduous forest. J Geophys Res 108(D20):Art. No. 4631. doi:4610.1029/2003JD003766 
Hirsch AI, Trumbore SE, Goulden ML (2004) The surface $\mathrm{CO}_{2}$ gradient and pore-space storage flux in a high-porosity litter layer. Tellus Ser B Chem Phys Meteorol 56(4):312-321

Högberg P, Read DJ (2006) Towards a more plant physiological perspective on soil ecology. Trends Ecol Evol 21(10):548-554

Högberg P, Hogberg MN, Gottlicher SG, Betson NR, Keel SG, Metcalfe DB, Campbell C, Schindlbacher A, Hurry V, Lundmark T, Linder S, Nasholm T (2008) High temporal resolution tracing of photosynthate carbon from the tree canopy to forest soil microorganisms. New Phytol 177(1): 220-228

Hutchinson GL, Rochette P (2003) Non-flow-through steadystate chambers for measuring soil respiration: numerical evaluation of their performance. Soil Sci Soc Am J 67(1): 166-180

Irvine J, Law BE, Martin JG, Vickers D (2008) Interannual variation in soil $\mathrm{CO}_{2}$ efflux and the response of root respiration to climate and canopy gas exchange in mature ponderosa pine. Glob Change Biol 14(12):2848-2859

Jarvis P, Rey A, Petsikos C, Wingate L, Rayment M, Pereira J, Banza J, David J, Miglietta F, Borghetti M, Manca G, Valentini R (2007) Drying and wetting of Mediterranean soils stimulates decomposition and carbon dioxide emission: the "Birch effect". Tree Physiol 27(7):929-940

Jassal RS, Black TA, Drewitt GB, Novak MD, Gaumont-Guay $\mathrm{D}$, Nesic Z (2004) A model of the production and transport of $\mathrm{CO}_{2}$ in soil: predicting soil $\mathrm{CO}_{2}$ concentrations and $\mathrm{CO}_{2}$ efflux from a forest floor. Agric For Meteorol 124(3-4): 219-236

Jassal R, Black A, Novak M, Morgenstern K, Nesic Z, Gaumont-Guay D (2005) Relationship between soil $\mathrm{CO}_{2}$ concentrations and forest-floor $\mathrm{CO}_{2}$ effluxes. Agric For Meteorol 130(3-4):176-192

Kramer C, Gleixner G (2006) Variable use of plant- and soilderived carbon by microorganisms in agricultural soils. Soil Biol Biochem 38(11):3267-3278

Kramer C, Trumbore S, Froberg M, Cisneros Dozal LM, Zhang D, Xu X, Santos GM, Hanson PJ (2010) Recent $(<4$ year old) leaf litter is not a major source of microbial carbon in a temperate forest mineral soil. Soil Biol Biochem 42:1028-1037

Kuzyakov Y (2006) Sources of $\mathrm{CO}_{2}$ efflux from soil and review of partitioning methods. Soil Biol Biochem 38(3):425-448

Kuzyakov Y, Gavrichkova O (2010) Time lag between photosynthesis and $\mathrm{CO}_{2}$ efflux from soil: a review. Glob Change Biol. doi:10.1111/j.1365-2486.2010.02179.x

Lavigne MB, Ryan MG, Anderson DE, Baldocchi DD, Crill PM, Fitzjarrald DR, Goulden ML, Gower ST, Massheder JM, McCaughey JH, Rayment M, Striegl RG (1997) Comparing nocturnal eddy covariance measurements to estimates of ecosystem respiration made by scaling chamber measurements at six coniferous boreal sites. J Geophys Res Atmos 102(D24):28977-28985

Levin I, Hesshaimer V (2000) Radiocarbon-a unique tracer of global carbon cycle dynamics. Radiocarbon 42(1):69-80

Lundegardh H (1927) Carbon dioxide evolution of soil and crop growth. Soil Sci 23(6):417-453

Luo YQ, Weng ES, Wu XW, Gao C, Zhou XH, Zhang L (2009) Parameter identifiability, constraint, and equifinality in data assimilation with ecosystem models. Ecol Appl 19(3):571-574

Mahecha MD, Reichstein M, Jung M, Seneviratne SI, Zaehle S, Beer C, Braakhekke MC, Carvalhais N, Lange H, Le Maire G, Moors E (2010) Comparing observations and processbased simulations of biosphere-atmosphere exchanges on multiple timescales. J Geophys Res Biogeosci 115:GO2003

Moffat AM, Papale D, Reichstein M, Hollinger DY, Richardson AD, Barr AG, Beckstein C, Braswell BH, Churkina G, Desai AR, Falge E, Gove JH, Heimann M, Hui DF, Jarvis AJ, Kattge J, Noormets A, Stauch VJ (2007) Comprehensive comparison of gap-filling techniques for eddy covariance net carbon fluxes. Agric For Meteorol 147(3-4): 209-232

Morner NA, Etiope G (2002) Carbon degassing from the lithosphere. Glob Planet Change 33(1-2):185-203

Muhr J, Borken W (2009) Delayed recovery of soil respiration after wetting of dry soil further reduces $\mathrm{C}$ losses from a Norway spruce forest soil. J Geophys Res. doi:10.1029/ 2009JG000998

Muhr J, Borken W, Matzner E (2009) Effects of soil frost on soil respiration and its radiocarbon signature in a Norway spruce forest soil. Glob Change Biol 15(4):782-793

Papale D, Reichstein M, Aubinet M, Canfora E, Bernhofer C, Kutsch W, Longdoz B, Rambal S, Valentini R, Vesala T, Yakir D (2006) Towards a standardized processing of net ecosystem exchange measured with eddy covariance technique: algorithms and uncertainty estimation. Biogeosciences 3(4):571-583

Pataki DE, Ellsworth DS, Evans RD, Gonzalez-Meler M, King J, Leavitt SW, Lin GH, Matamala R, Pendall E, Siegwolf R, Van Kessel C, Ehleringer JR (2003) Tracing changes in ecosystem function under elevated carbon dioxide conditions. Bioscience 53(9):805-818

Paterson E, Midwood AJ, Millard P (2009) Through the eye of the needle: a review of isotope approaches to quantify microbial processes mediating soil carbon balance. New Phytol 184(1):19-33

Pendall E, Bridgham S, Hanson PJ, Hungate B, Kicklighter DW, Johnson DW, Law BE, Luo YQ, Megonigal JP, Olsrud M, Ryan MG, Wan SQ (2004) Below-ground process responses to elevated $\mathrm{CO}_{2}$ and temperature: a discussion of observations, measurement methods, and models. New Phytol 162(2):311-322

Pumpanen J, Ilvesniemi H, Hari P (2003) A process-based model for predicting soil carbon dioxide efflux and concentration. Soil Sci Soc Am J 67(2):402-413

Pumpanen J, Kolari P, Ilvesniemi H, Minkkinen K, Vesala T, Niinisto S, Lohila A, Larmola T, Morero M, Pihlatie M, Janssens I, Yuste JC, Grunzweig JM, Reth S, Subke JA, Savage K, Kutsch W, Ostreng G, Ziegler W, Anthoni P, Lindroth A, Hari P (2004) Comparison of different chamber techniques for measuring soil $\mathrm{CO}_{2}$ efflux. Agric For Meteorol 123(3-4):159-176

Pumpanen J, Ilvesniemi H, Kulmala L, Siivola E, Laakso H, Kolari P, Helenelund C, Laakso M, Uusimaa M, Hari P (2008) Respiration in boreal forest soil as determined from carbon dioxide concentration profile. Soil Sci Soc Am J 72(5):1187-1196

Raich JW, Schlesinger WH (1992) The global carbon dioxide flux in soil respiration and its relationship to vegetation 
and climate. Tellus Ser B Chem Phys Meteorol 44(2): 81-99

Raich JW, Tufekcioglu A (2000) Vegetation and soil respiration: correlations and controls. Biogeochemistry 48(1): 71-90

Reichert P (1997) On the necessity of using imprecise probabilities for modelling environmental systems. Water Sci Technol 36(5):149-156

Reichstein M, Beer C (2008) Soil respiration across scales: the importance of a model-data integration framework for data interpretation. J Plant Nutr Soil Sci Zeitschrift Fur Pflanzenernahrung Und Bodenkunde 171(3):344-354

Reichstein M, Falge E, Baldocchi D, Papale D, Aubinet M, Berbigier P, Bernhofer C, Buchmann N, Gilmanov T, Granier A, Grunwald T, Havrankova K, Ilvesniemi H, Janous D, Knohl A, Laurila T, Lohila A, Loustau D, Matteucci G, Meyers T, Miglietta F, Ourcival JM, Pumpanen J, Rambal S, Rotenberg E, Sanz M, Tenhunen J, Seufert G, Vaccari F, Vesala T, Yakir D, Valentini R (2005) On the separation of net ecosystem exchange into assimilation and ecosystem respiration: review and improved algorithm. Glob Change Biol 11(9):1424-1439

Risk D, Kellman L, Beltrami H (2002a) Carbon dioxide in soil profiles: production and temperature dependence. Geophys Res Lett 29(6):1087. doi:1010.1029/2001GL014002

Risk D, Kellman L, Beltrami H (2002b) Soil $\mathrm{CO}_{2}$ production and surface flux at four climate observatories in eastern Canada. Glob Biogeochem Cycl 16(4):1122. doi: 1110.1029/2001GB001831

Rochette P, Gregorich EG, Desjardins RL (1992) Comparison of static and dynamic closed chambers for measurement of soil respiration under field conditions. Can J Soil Sci 72(4):605-609

Ryan MG, Law BE (2005) Interpreting, measuring, and modeling soil respiration. Biogeochemistry 73(1):3-27

Santos GM, Moore RB, Southon JR, Griffin S, Hinger E, Zhang D (2007a) AMS C-14 sample preparation at the KCCAMS/UCI facility: status report and performance of small samples. Radiocarbon 49(2):255-269

Santos GM, Southon JR, Griffin S, Beaupre SR, Druffel ERM (2007b) Ultra small-mass AMS C-14 sample preparation and analyses at KCCAMS/UCI facility. Nucl Instrum Methods Phys Res Sect B Beam Interact Mater At 259(1):293-302

Savage KE, Davidson EA (2003) A comparison of manual and automated systems for soil $\mathrm{CO}_{2}$ flux measurements: tradeoffs between spatial and temporal resolution. J Exp Bot 54(384):891-899

Savage K, Davidson EA, Richardson AD (2008) A conceptual and practical approach to data quality and analysis procedures for high-frequency soil respiration measurements. Funct Ecol 22(6):1000-1007

Schuur EAG, Trumbore SE (2006) Partitioning sources of soil respiration in boreal black spruce forest using radiocarbon. Glob Change Biol 12(2):165-176

Šimůnek J, Suarez DL (1993) Modeling of carbon-dioxide transport and production in soil. 1. Model development. Water Resour Res 29(2):487-497

Subke JA, Inglima I, Cotrufo MF (2006) Trends and methodological impacts in soil $\mathrm{CO}_{2}$ efflux partitioning: a metaanalytical review. Glob Change Biol 12(6):921-943
Tang J, Baldocchi DD, Xu L (2005a) Tree photosynthesis modulates soil respiration on a diurnal time scale. Glob Change Biol 11:1298-1304

Tang J, Misson L, Gershenson A, Cheng WX, Goldstein AH (2005b) Continuous measurements of soil respiration with and without roots in a ponderosa pine plantation in the Sierra Nevada Mountains. Agric For Meteorol 132(3-4): 212-227

Torrence C, Compo GP (1998) A practical guide to wavelet analysis. Bull Am Meteorol Soc 79(1):61-78

Trumbore S (2000) Age of soil organic matter and soil respiration: radiocarbon constraints on belowground $\mathrm{C}$ dynamics. Ecol Appl 10(2):399-411

Trumbore S (2006) Carbon respired by terrestrial ecosystems-recent progress and challenges. Glob Change Biol 12:141-153

Trumbore S (2009) Radiocarbon and soil carbon dynamics. Annu Rev Earth Planet Sci 37:47-66

Turcu VE, Jones SB, Or D (2005) Continuous soil carbon dioxide and oxygen measurements and estimation of gradient-based gaseous flux. Vadose Zone J 4:1161-1169

Valentini R, DeAngelis P, Matteucci G, Monaco R, Dore S, Mugnozza GES (1996) Seasonal net carbon dioxide exchange of a beech forest with the atmosphere. Glob Change Biol 2(3):199-207

Van Oijen M, Rougier J, Smith R (2005) Bayesian calibration of process-based forest models: bridging the gap between models and data. Tree Physiol 25(7):915-927

Vargas R, Allen MF (2008a) Diel patterns of soil respiration in a tropical forest after Hurricane Wilma. J Geophys Res Biogeosci 113(G3):G03021

Vargas R, Allen MF (2008b) Environmental controls and the influence of vegetation type, fine roots and rhizomorphs on diel and seasonal variation in soil respiration. New Phytol 179(2):460-471

Vargas R, Baldocchi DD, Allen MF, Bahn M, Black TA, Collins SL, Curiel Yuste J, Hirano T, Jassal RS, Pumpanen J, Tang J (2010a) Looking deeper into the soil: biophysical controls and seasonal lags of soil $\mathrm{CO}_{2}$ production and efflux. Ecol Appl. doi:10.1890/09-0693

Vargas R, Detto M, Baldocchi DD, Allen MF (2010b) Multiscale analysis of temporal variability of soil $\mathrm{CO}_{2}$ production as influenced by weather and vegetation. Glob Change Biol 16:1589-1605. doi:10.1111/j.1365-2486.2009.02111.x

Wahl EH, Fidric B, Rella CW, Koulikov S, Kharlamov B, Tan S, Kachanov AA, Richman BA, Crosson ER, Paldus BA, Kalaskar S, Bowling DR (2006) Applications of cavity ring-down spectroscopy to high precision isotope ratio measurement of C-13/C-12 in carbon dioxide. Isot Environ Health Stud 42(1):21-35

Williams M, Richardson AD, Reichstein M, Stoy PC, Peylin P, Verbeeck H, Carvalhais N, Jung M, Hollinger DY, Kattge J, Leuning R, Luo Y, Tomelleri E, Trudinger CM, Wang YP (2009) Improving land surface models with FLUXNET data. Biogeosciences 6(7):1341-1359

Wutzler T, Reichstein M (2008) Colimitation of decomposition by substrate and decomposers-a comparison of model formulations. Biogeosciences 5(3):749-759

Xu LK, Baldocchi DD (2004) Seasonal variation in carbon dioxide exchange over a Mediterranean annual grassland in California. Agric For Meteorol 123(1-2):79-96 